\title{
Why is Economics not a Complex Systems Science?*
}

John Foster, Why is Economics not a Complex Systems Science? Discussion Paper No. 336, December 2004, School of Economics, The University of Queensland.

\section{Abstract}

Economics is viewed as a discipline that is mainly concerned with 'simplistic' theorizing, centered upon constrained optimization. As such, it is ahistorical and outcome focused, ie, it does not deal with economic processes. It is argued that all parts of the economy are inhabited by complex adaptive systems operating in complicated historical contexts and that this should be acknowledged at the core of economic analysis. It is explained how economics changes in fundamental ways when such a perspective is adopted, even if the presumption that people will try to optimize subject to constraints is retained. This is illustrated through discussion of how the production function construct has been used to provide an abstract representation of the network structures that exist in complex adaptive systems such as firms. It is argued that this has led to a serious understatement of the importance of rule systems that govern the connections in productive networks. The macroeconomics of John Maynard Keynes is then revisited to provide an example of how some economists in earlier times were able to provide powerful economic analysis that was based on intuitions that we can now classify as belonging to complex systems perspective on the economy. Throughout the paper, the reasons why a complex systems perspective did not develop in the mainstream of economics in the $20^{\text {th }}$ Century, despite the massive popularity of an economist like Keynes, are discussed and this is returned to in the concluding section where the prospect of paradigmatic change occurring in the future is evaluated.

\author{
The School of Economics \\ The University of Queensland \\ Brisbane \\ Queensland 4072 \\ Australia \\ j.foster@economics.uq.edu.au
}

\footnotetext{
* This paper is an expanded part of a longer paper, originally entitled "A simple representation of the economic behavior of a complex adaptive system: from Schumpeter's insights towards a general non-equilibrium theory,” that was presented at the International J.A. Schumpeter Society Conference at Bocconi University, Milano, $9^{\text {th }}-12^{\text {th }}$ June 2004 . I would like to thank all participants who offered comments on that presentation. Thanks are also due to Jason Potts for his comments on an early draft of that paper. The usual caveat applies.
} 


\section{Why is Economics not a \\ Complex Systems Science?*}

John Foster, Why is Economics not a Complex Systems Science? Discussion Paper No. 336, January 2005, School of Economics, The University of Queensland.

\section{Introduction}

Over the past two decades, an increasing number of natural scientists have adopted a 'complex systems' approach in analyzing and modeling the behavior of energy using systems in the chemical, physical and biological domains. Although it continues to make good scientific sense to examine, both analytically and empirically, how the component parts of a system behave at the microscopic level, there are key connective properties that all systems possess in uncontrolled conditions that cannot be discerned through such scientific reduction [Potts [2000]]. Complex system science examines the connective properties that exist between the elements of systems to discover forms of order that can be represented analytically in terms of, for example, graph theory, network analysis, power laws, diffusion models, agent-based simulation and replicator dynamics.

Depending on the kind of system that we are dealing with, the order we observe can range from deterministic chaos through to the purposeful creation and destruction of connections in complex adaptive systems. Gradually, an analytical toolkit has been developed that can be used in a range of different contexts, both to understand the historical dynamics of complex systems and, in some cases, to predict their likely time paths. ${ }^{1}$

\footnotetext{
${ }^{1}$ See Holland [1995] and Kauffman [1993] for examples in a biological context.
} 
The economic system and its component sub-systems are, undeniably, 'complex adaptive systems'. ${ }^{2}$ Why does this matter to economists who now have at their disposal a vast array of sophisticated analytical tools that can be employed to explain virtually all aspects of economic behavior? It is easy to think that the cognitive sophistication [or 'rationality'] that we observe in human beings is the overwhelmingly most important reason why we observe behavior that we can label as 'economic' and, therefore, there is little need to follow the lead of some evolutionary biologists ${ }^{3}$, psychologists ${ }^{4}$ and management scientists ${ }^{5}$ who feel that all living systems have to be viewed as complex systems before their behavior in the space/time continuum can be understood. Because economic behavior is seen as uniquely different, many economists are happy to continue to work within the boundaries of modern economic theory, particularly since game theory entered the theoretical core of economics, rather than to attempt to rethink what they do from a complex systems perspective.

However, the public at large and policymakers seem to be much less enthusiastic about modern economics than they were in the days when it was a less sophisticated, i.e., a less mathematical, discipline. Some economists will tell you that this is because economics has become more about the operation of 'free markets' than it was and that this loss of

\footnotetext{
${ }^{2}$ See Foster [2005] for definitions of different kinds of complex systems.

${ }^{3}$ See Depew and Weber [1995] who argue that natural selection explanations evolution are incomplete unless they are set within a complex systems framework.

${ }^{4}$ See Byrne [1998] for discussion of how complex system theory can be applied in the social sciences.

${ }^{5}$ See, for example, Axelrod and Cohen [1999], McElroy [2002], McKelvey [1999] and Stacey [1996].
} 
popularity is not because of the presence of complicated mathematics but because hardnosed neoclassical economic doctrine has never been palatable to those wishing to exploit or to 'free ride' on others. It is true that, at least since the time of Adam Smith, economic doctrine, based on the promotion of self-interest and free markets, has not always been popular amongst those enjoying economic rents on the political right or those subject to exploitation on the left, irrespective of whether it is represented in words or in equations. But such a defense implies that we are dealing, primarily, with an ideology rather than a science or, at least, what is a science is being viewed from an ideological perspective by some members of the public. As a vehicle for ideology, complicated mathematics has a great deal of rhetorical power, appearing to the public as a product of scientific endeavors - in television and film, economists invariably appear in front of a black or white board on which are written sets of equations. But, at the same time, the economist is usually portrayed in jokes as logical to the point of absurdity. What was a discipline borne out of very practical considerations is portrayed by some as unworldly and of little use.

Despite popular skepticism concerning the realism of economics and of its scientific credentials, it is still widely seen as a very useful and constructive 'way of thinking' about human behavior. If this is the case then it is valid to think of it, at least in part, as a form of ideology, but it is very important ideology because it is often viewed as a body of ideas that helps to hold market capitalism together. However, this poses a problem because, when a science has to bear ideological burdens, it is likely that scientific progress will be held back. Thus, we may not see scientific revolutions of the type 
identified by Thomas Kuhn very often and, furthermore, the 'protective belt' that forms around a theoretical core, as discussed by Imre Lakatos, will be very difficult to breach.

It will be argued here that thinking about the economy and its sub-components as complex adaptive systems can enable economics to break out of this scientific impasse. This has been made possible by the fact that game theory, with its situation specific logic, has eliminated most of the simplistic theoretical generalizations that used to be employed in neo-liberal economic ideology. Instead, economics now offers a vast game-theoretical tool kit that is undeniably 'scientific' in content and can address a wide range of observed economic interactions. Nowadays, economists are becoming highly specialized scientific experts. In the post Cold War era, sweeping generalizations of the ideological kind tend to be promulgated by political philosophers. The specialization that has occurred in the community of economists has, however, made it difficult to make connections with advances in complex systems science lying outside economics, in the natural sciences and, to a lesser extent, in parts of the social sciences. Such connections are in evidence in heterodox economics ${ }^{6}$ and there are indications that some game theorists have been moving in this direction ${ }^{7}$.

As we shall see, the slow uptake of the complex systems perspective is not only because of increased specialization in economics but also because it constitutes a rather

\footnotetext{
${ }^{6}$ See Foley [2003], Rosser [1999] and Velupillai [2000]

${ }^{7}$ Sent [2004] points out that some game theorists do now accept that the economic system is complex in the Simonian sense and have formally incorporated bounded rationality into their models. This tends to alter significantly model predictions in comparison with standard treatments.
} 
fundamental departure from the commonly held mental models that economists espouse. Mainstream economics relies heavily upon constrained optimization, both in interactive and non-interactive settings, as its theoretical foundation. As such, it has produced some very useful insights into why certain kinds of economic behavior are observed. Of course, there has been an unending stream of criticisms of this kind of economics, at least as far back as Veblen [1898], in terms of its capacity to explain and predict economic events unfolding in historical time. Even one of the founding fathers of modern neoclassical economics, Alfred Marshall, felt that such theory should only be permitted to address historical events over short periods, although it was viewed as quite permissible to let a theory with good short period credentials unfold into is logical 'long run’ if it was felt that this could provide some insight to those engaged in the formulation of economic policy [Foster [1993]]. History deals with complicated interactions over time and, as is also the case in the natural sciences, one cannot expect any simple theory, cast in ideal conditions, to tell us all that much about these. Theory that is specified outside the historical time dimension is doomed to be isolated from the flow of events in history. Such theory is logically rich but scientifically poor.

Karl Popper [1944,1945] warned of the great dangers involved in trying to get round this problem by adopting 'historicism', i.e., trying to predict the course of history through unconditional theorizing in contexts that involve open systems and evolutionary change and he robustly admonished those, such as Karl Marx, who had converted historical trends into deterministic 'laws of history'. Modern economists have, on the one hand, adhered to this Popperian position by insisting that theory and history should be separate 
domains yet, on the other hand, they have often breached the Popperian maxim by arguing that historical trends can be 'explained' by theoretical propositions that are not combinations of conditional theoretical statements, supported by laboratory experimentation in ideal conditions, but theories concerning abstract logical tendencies towards never existing 'long run' equilibrium states. Thus, 'real business cycle’ theorists have proposed idealized optimal planning models that are subject to exogenous technological shocks and asserted that there is evidence in support of such theories in the macroeconomic tendencies that we actually observe ${ }^{8}$. From a Popperian perspective, this is seriously bad science that, furthermore, leads to the opposite of Popper's own view that, in the social domain, policy-making should be pragmatic and piecemeal, with new policies tested, as and when deemed necessary.

From the Popperian perspective, modern economics confronts a fundamental difficulty it is inadmissible to use formal economic theorizing of the neoclassical type to make predictions concerning the future, or even predictions concerning past historical events since the choice of [untested] conditional relations is subjective and the result of such analytics is not necessarily superior to the informed judgment of a historian employing intuition and heuristics. There is nothing new in noting this problem - Friedrich von Hayek stated it clearly in the 1950 s. $^{9}$ However, today the landscape is different because we now have a body of complex systems science in which it is argued that flows of

\footnotetext{
${ }^{8}$ Contrast this with the insightful account of economic growth and development by Freeman and Louça [2001] as continual structural change as complex adaptive systems interact.

${ }^{9}$ See Hayek [1952] and, more recently, Vanberg [2004].
} 
events in history, although they look very complicated and difficult to analyze, can, in fact, be due to the operation of quite simple rules. Does this mean that modern economics is vindicated in the sense that it is, after all, acceptable to think of simple theoretical idealizations as lurking beneath the flow of historical events? Or does it mean that we have to think in an entirely new way about theory in the economic domain?

These are very big questions and they cannot be answered in any complete way in an article of this length. Instead, only two objectives are pursued here. The first objective is to explain why complex adaptive systems theory is fundamentally different to standard economic theory that has at its core constrained optimization. The second objective is to illustrate why this is important through an examination of the role of the production function construct in economics. To emphasize the point that the complex systems perspective is not entirely new in economics, John Maynard Keynes’ treatment of production and processes in his General Theory is viewed from such a standpoint.

\section{Complex versus Simplistic Perspectives on Economic Systems}

Standard economic theory centers upon constrained optimization in the allocation of resources, factors of production and goods/services in the face of scarcity. It is theory that deals with outcomes, mainly point equilibria that can be deduced analytically. However, in recent times, more sophisticated notions of equilibrium states, namely, equilibrium curves, e.g., limit cycles, and equilibrium regions, e.g., chaotic domains with 'strange attractors', have become more common in so called 'dynamic' variants of economic 
theory. However, expanding the notion of an equilibrium state in this way has not been particularly helpful because it has made things much more mathematically complicated, reducing the predictive power of economic theory and rendering invalid simple and easy to understand explanations of economic phenomena [Weintraub [2002]]. Correspondingly, difficulty in obtaining equilibrium solutions in the presence of nonlinearity has led to a shift away from mathematical deduction towards numerical methods. Also, because it is difficult to connect such mathematically complicated theories with the temporally arranged economic data at our disposal, there has been an increased reliance on simulation and calibration over traditional econometric methods.

The problem with theories of outcomes, either in simple linear form or in complicated nonlinear form, is that they do not capture the processes that occur in the history of the economic system. A theory of outcomes and a history of processes, as reflected in the monetary valued historical data at our disposal, can only be connected by ad hoc contrivances such as presumed 'disequilibrium dynamics'. However, such dynamics do not and cannot capture economic processes but, rather, they are mathematical constructions that are necessary before movements in data series can be connected with equilibrium outcome theories. Fundamental questions immediately arise concerning the scientific value of such theorizing, both in terms of its explanatory power and predictive content. The presence of ad hoc dynamics permits a number of different hypotheses, drawn from quite different theoretical models, to find support in the same set of historical data. Observational equivalence problems always arise in science when two hypotheses, one drawn from theory and another that is ad hoc are tested jointly. 
In a chemistry experiment this is much less likely to happen because of the intimate and direct relationship between the process under examination, the data that is generated and the hypothesis being tested. Why is this the case? Because experimental controls are applied in order to focus attention on a particular process of interest. These controls are not abstract assumptions that relate to a timeless body of theory but, rather, they are real forces that exist in the space/time continuum in which processes unfold. To put it another way, the [controlled] system within which a process is examined is well understood. The problem in economics arises because, when the only available data are time series, the process in question cannot be studied through a controlled experiment. The mixture of fundamental axioms and qualifying assumptions that is employed instead does not result in a close connection between process, data and hypothesis.

The systems that we deal with in the economic domain can range from the individual [a psychological system] to the whole economy [a macroeconomic system]. These systems are not straightforward to deal with because they are complicated and interconnected with other non-economic systems such as social, political, biological and ecological systems. In the face of this scientific difficulty, the most popular approach in the modern era has been to propose that the economic behavior that we observe in reality can be viewed as the solution [static or dynamic] of an optimization problem in the presence of constraints. This is made manageable and analytically tractable by using a range of 'simplifying' assumptions. 
A frequent assumption is to remove the historical dimension of time. Attempts are made to relate the resultant timeless [or reversible time] abstraction to the reality of historical time in two main ways. First, it can be pretended that the abstraction represents a simplified characterization of an actual system moving through historical time in a series of snapshots and that reality can be approached by the successive relaxation of assumptions. Second, reality can be viewed a deviation from an idealized abstract state, i.e., the real world is characterized by 'disequilibrium', 'inefficiency', etc [analogous to the effect of friction in physics]. In Foster [2005], it is argued that neither of these approaches to linking abstract theory with reality are scientifically valid in any general sense because, in neither case, are the abstractions used true simplifications of the behavior of a system in the historical dimension, as is the case in the chemical experiment in the laboratory.

Such abstractions are simplistic in construction and, by definition, ontologically separate from the behavior that we observe in history. Because of this, it is inappropriate to employ them directly in explaining the actual behavior of systems. However, as Alfred Marshall argued, simplistic models can be enlightening in studying, for example, price movements in very local space/time contexts. In other words, if the time period is short enough, the environment stays still enough to allow something analogous to a controlled experiment to occur. Thus, the simplistic assumption of 'perfect knowledge' is acceptable if the choice set is very narrow and there is considerable familiarity with the local environment. 
Many economists, however, go much further than this and claim that simplistic abstractions provide intuitive insights in a much more general sense. It has been argued that they can provide insights into how what appear to be impossibly complicated historical processes work on the ground that those who do optimize subject to constraints are likely to survive better than those who don't. This is an old idea, dating back to Alchian [1950] and Friedman [1953], who both suggested that the operation of selection mechanisms could mean that neoclassical economic propositions concerning outcomes, based on timeless constrained optimization, should show through in actual economic behavior. Despite the fact that it is very easy to refute such suggestions [see Penrose [1952]], this notion has lingered on in the minds of many economists to the present day.

Selection mechanisms are, of course, closely associated with the work of evolutionary economists but it is made clear in this heterodox tradition that such mechanisms can only be meaningful if they are set in an analytical framework that allows novelty and variety to exist and structural change to occur in systems that are open, not closed [Metcalfe [1998]]. Selection is a process that can only occur in systems that are complex and adaptive and the economic system and its component sub-systems are all examples of complex adaptive systems [Foster and Metcalfe [2001]]. A firm is an excellent example but the standard approaches to dealing with these systems involve simplistic theorizing, i.e., their histories are viewed as disequilibrium tendencies towards idealized states or it is pretended that an idealized, timeless state is a simple skeletal representation of the system at any point in time with 'history' being due to the impact of exogenous shocks. 
At first glance, the notion of a complex adaptive system seems to involve very complicated behavior that is difficult to deal with analytically. However, the term 'complex' relates to a state of 'ordered complicatedness', ie, we are dealing with a system that is a network structure which derives its integrity from a set of rules [see Foster [2005]]. Once we actually try to address the question of what kind of system we are dealing with, theorizing takes on a new meaning. First of all, we can theorize about the kind of connective structure, i.e., rules, we are dealing with and, second, we can theorize about the processes that such a system experiences/initiates within the context of such rules. Despite the apparent complicatedness of a complex system, the set of rules that it adopts and the associated processes can be quite simple to represent analytically.

Importantly, complex adaptive systems are all 'dissipative structures', i.e., systems that are capable of maintaining themselves and growing through the processing of free energy. The principles that govern the behavior of dissipative structures in physiochemical and biological setting are becoming well understood and this has been helpful in beginning to understand how economic systems behave [Foster [2000a]]. However, in the economic domain, these principles operate somewhat differently because of the much greater role that knowledge has in releasing and deploying free energy. What is common to studies of the behavior of all dissipative structures is the necessity that the principles that govern such behavior are set, explicitly, in the historical domain. The paths that are followed in time are non-equilibrium, not dis-equilibrium, and predominantly endogenous in character as energy, materials and information are drawn in by such 
systems. Of course, exogenous shocks have to be dealt with but these affect the nonequilibrium trajectory that a system follows, not an equilibrium outcome ideal state.

Standard economic theory involves the use of an ahistorical body of logical propositions to represent tendencies observed in the historical domain. In contrast, complex adaptive system theory deals directly with the underlying principles that govern the behavior of systems in history. Such theory remains an abstraction, as all theory should be, but one concerning the rules that govern the connections between elements in a complex system and how these rules change over time. For the purpose of analysis, these rules must be represented abstractly but they remain stylized versions of actual rules operating in systems over time. Constrained optimization is not abandoned since it figures in the set of rules that can be applied in economic settings. For example, most firms these days use software that can optimize the inventories they hold in terms of material prices, both spot and forward, the cost of capital and anticipated demand within the firm. However, in other areas of the firm, problems with respect to joint products and discrete commitments over long time horizons preclude the use of conventional constrained optimization algorithms and, instead, other kinds of rules are applied.

From this perspective, the mathematical logic applied in constrained optimization is a special case in a set of algorithmic representations of the rules that govern agent behavior. Genetic algorithms can yield optimal solutions suggested by the mathematics of constrained optimization if conditions remain static enough. However, in an evolving system, constrained optimization is not a rule that makes sense in most circumstances. As 
Velapullai [2000] explains, it is a rule that is often non-computable from an algorithmic perspective. The various rules that are adopted in productive organizations lead to the formation of network structures that have a degree of irreversibility, severely restricting the extent to which the logic of optimization can be applied. However, despite this, there are a multitude of examples in productive organizations of mathematics being applied in order that processes can run more smoothly. The use of mathematics is vital in engineering, as it is in cost accounting. Furthermore, many rules can be expressed mathematically but this does not automatically mean that it is relevant or useful to presume that constrained optimization is the dominant rule.

Mathematics can be used deductively at different levels. Constrained optimization offers a solution in terms of the best combination elements to attain a desired goal. However, mathematics can also be used in a less exotic ways, for example, to explore the logical relationships between variables because of accounting rules or of income/expenditure feedbacks. Also, it is often possible to track movements in aggregate growth indicators that reflect underlying developmental processes. For example, Foster and Wild [1999] show how self-organizational development can be captured by the simple logistic equation, augmented by conventional economic propositions, and that this provides an understanding of the growth of a system in its environment that is not available at lower levels of aggregation. By definition, mathematical expressions are deterministic yet they still remain useful in summarizing historical tendencies that may contain non- 
deterministic elements. However, acceptance of this descriptive role of mathematics proscribes the extent to which logical exercises in deduction can be conducted. ${ }^{10}$

Economists, compared with, for example, biologists, have a distinct advantage in tracking developmental processes because economic structures and processes have monetary valuations and thus, it is possible to use mathematics to track asset valuations and streams of aggregated data. However, over the past three decades, many economists have demanded that the quantifiable trends observed in economic data should be viewed as the outcomes economic behavior at the microeconomic level. To this end, theoretical 'microfoundations' have been proposed. What these usually amount to is constrained optimization by a 'representative' agent. From the perspective of complex systems theory and the associated view of systems as network structures, what is being asserted is that value emanates from the elements that make up a system, not from the connections between them. This is a distinctly odd way of looking at a system because unacceptably strong assumptions have to be made about connections and about the homogeneity of elements. If everything is connected to everything else ['perfect knowledge'] then there is no real distinction between elements and systems. As Mirowski [1989] perceptively observed, this 'force field' conception of a system, that originated in physics over a century ago, became commonplace in the general equilibrium economics that emerged in the course of the $20^{\text {th }}$ Century.

\footnotetext{
${ }^{10}$ See Foster and Wild [1999] p.754
} 
However, this does not mean that individuals do not attempt to engage in constrained optimization when they can. Indeed, it is almost tautological that they do. What is crucial is the nature of the environment in which optimization takes place and whether this can be represented analytically. The simplistic systems that populate economic theory are assumed to contain elements that are fully connected and this necessitates a range of abstract assumptions. ${ }^{11}$ Complex systems are never fully connected, they are partially connected, have actual and potential connections with other systems, i.e., they are open, and they are constantly undergoing structural change as old connections break, new ones form and [heterogeneous] elements come and go. There is no doubt that constrained optimization occurs in complex systems but the goals of behavior, the processes that are enacted and the constraints that are faced all change continually. The more pronounced these changes are, the less relevant is formal constrained optimization in understanding the economic behavior that we observe over time [Bowles and Gintis [2000]]. However, as we have noted, we can find instances when there is enough steadiness in goals, processes and constraints to allow constrained optimization to be the dominating rule in the face of very sparse elements and appropriate flexibility in certain connections, i.e., over very short time periods and limited choice domains. This was how Alfred Marshall originally viewed constrained optimization as an analytical tool [Foster [1993]].

Over longer periods, the presence of uncertainty induces a tendency to adopt other rules, in the form of habits, routines, conventions and norms, which are just as rational in such

\footnotetext{
${ }^{11}$ When full connectivity does not prevail there is deemed to be 'market failure' of 'information asymmetry', etc. which implies, incorrectly, that the fully connected state is attainable.
} 
conditions [Bowles and Gintis [2000]]. These can be thought of analytically from a transactions cost perspective [Williamson [1985]], but not empirically for the simple reason that transactions costs cannot be measured except in very specific instances. ${ }^{12}$ The adoption of simple, non-calculative rules, with their low management costs, has the great advantage of freeing up time and other resources for the pursuit of new income streams. However, adopted rules of this form gradually lose their relevance as the environment changes and they are eventually abandoned, i.e., they are not given up through marginal adjustments. Why? Because alternatives cannot always be taken up on the basis of marginal calculation, either because choices are discrete and lumpy or because there is insufficient information available that is suitable for forming probabilities and associated calculations of expected values. Complex worlds are explored in order to make discoveries, they rarely contain data upon which optimal solutions can be calculated using mathematics. It is for this reason that the adoption of routines and habits can be viewed as entirely rational from a complex systems perspective.

The network structures that we find in complex adaptive systems are a product of learning and experimentation that forges new connections between elements. Because some network structures are fundamental to the emergence of other network structures, they become tightly bonded, emphasising reliability, rather than adaptability. Thus, growth, measured in terms of input or output flows, is the outcome of a cumulative

\footnotetext{
${ }^{12}$ Using game theory, Anderlini and Felli [2001] show that the presence of transactions costs renders the Coase Theorem, concerning the emergent of efficient outcomes in negotiation, i.e., in complex settings, invalid.
} 
process, whereby ordered complexity increases, with tight network structures in the core and loose ones on the periphery. Such systems face boundaries on their growth that can be internal or external. Internal boundaries relate to inflexibilities and breakdowns that arise over time because of network irreversibilities and entropy processes. ${ }^{13}$ External boundaries involve the impact of other systems. The key constraints over longer time periods are the boundaries that systems face when they are more developed. These can be energetic in character, they can be about knowledge limitations or due to the interactive ecology of systems. They all imply that growth cannot go on indefinitely. Human creativity is the engine of novelty generation, continually creating opportunities for growth but income-expenditure identities imply that there must be displacement and replacement in expenditure patterns before 'developmental' growth can occur. In other words, selection processes must operate. In the literature on evolutionary economics, competitive selection is generally viewed as something that is faced by a maturing economic organization but, equally, highly useful innovative ideas may lie around for decades before they are actually selected at all - income-expenditure boundaries not only affect the mature, they also impact upon the emergent.

What breaks higher level income-expenditure limitations on growth is a capacity to extract more energy and resources, or more goods and services, from a given amount of expenditure on energy, materials and information and to have this rise in productivity generate IOUs that are accepted as a means of exchange. Thus, income can rise to allow

\footnotetext{
${ }^{13}$ See Brooks and Wiley [1986] for a discussion of how boundaries can be internally generated in the context of biological evolution.
} 
demand to be made effective for new output. Of course, if worthless IOUs are written and circulated we have an inflationary problem. Thus, those who accept new IOUs have to make subjective assessments concerning their worth - this is a dimension of knowledge and it is strongly linked to the accepted rules that operate in debtor assessment. ${ }^{14}$ Joseph Schumpeter understood this well, emphasizing that innovation and growth have to be paralleled by the extension of new credit. So, in complex adaptive systems in which heterogeneous products are valued in a common currency unit, it is the flow of funds that connect systems and their components, presenting both opportunities and limitations on what is possible. Thus, the state of effective demand [flows of funds now] and the availability of money to provide the reserve base upon which credit expansion can be built [flows of funds in the future] are crucial matters in complex adaptive systems of the economic kind. The neoclassical notion, that money is a 'veil' that doesn't matter, is not at all credible from this perspective.

If we accept that the economy and its components are complex adaptive systems, then the use of simplistic representations of systems reduces the relevance economic theory. This is what we have witnessed over the past half century. This has been most marked in macroeconomics which has, in the main, relied increasingly upon a general equilibrium perspective built upon neoclassical microeconomic theoretical foundations that were, paradoxically, rendered obsolete when game theory entered the core of microeconomics in the 1980s. However, although game theorists have shown that the operation of

\footnotetext{
${ }^{14}$ Foster [2005] refers to this as 'fourth order' complex behavior.
} 
constrained optimization in interactive settings yields a very complicated economy there is little sense of a 'system' that has emerged in the very extensive game theory literature. It is precisely because of this that game theory has only been used in a very limited way in macroeconomics. Dopfer, Foster and Potts [2004] note this difficulty with modern economics and argue that it is necessary to develop 'meso', rule based, theories that can be used to analyse the order that we observe in complex economic systems and to generate 'history-friendly' hypotheses, both in microeconomics and macroeconomics. To bring this point home, we shall now focus on a familiar and fundamental construct in economics, namely, the production function and, arguably, the $20^{\text {th }}$ Century's most famous economist, John Maynard Keynes.

\section{The Production Function and John Maynard Keynes}

The production function is a central conceptualization in economics. Despite the fact that using any aggregate version of such a function was discredited in the 'capital theory controversy' of the 1970s, it remains embedded in the core of mainstream economics. In Foster [2005] it was argued that it is not a suitable analytical construct to deal with production in complex, evolving economic systems. Although it is trivial to associate inputs with outputs over any chosen time period, in reality, such relations alter over time. This alteration can be large and can occur in both smooth and discontinuous forms. It has been argued [see Foster and Wild [1999]] that it is better to focus upon these processes of change over time, rather than to think in terms of timeless production function representations on the move. However, such a position introduces a range of questions 
concerning how we might deal analytically with the systemic change that we can observe going on complex adaptive systems in historical time.

The Foster and Wild approach was to weld conventional perspectives on economic theorizing on to diffusional value trajectories in historical time that should be manifest if self-organizational development is occurring. However, we must remember that temporal trajectories of data do not actually capture historical processes, only manifestations of them. Data are no more than quantitative indications that processes are ongoing in the time/space continuum. Such data may be, for example, about the volume and value of inputs or outputs. This 'data' and the 'process' by which inputs are transformed into outputs are intimately connected but they remain in the separate domains of the quantitative and the qualitative. It is this separation that delimits the extent to which we can provide abstract analysis of the processes that give rise to economic value. We have aggregations of value but, seemingly, no way of linking these with the patterns of activity that give rise to such value. How to deal with this has been one of the main bones of contention between orthodox and heterodox economists for at least a century. The former have preferred to keep theorizing about the determination of value largely away from historical context while the latter have preferred to eschew timeless theorizing in favour of historical investigations of economic processes.

This bifurcation in economics occurred in the late $19^{\text {th }}$ Century when 'marginalists' in England, France and Austria began to challenge the domination of economic historians, with their institutionalist orientation towards political economy. Back then, the German 
Historical School was the main source of institutional thinking in Europe. In the $20^{\text {th }}$ Century, this became a contest, increasingly fought out in the United States, between institutionalists and emergent neoclassical economists. The watershed in this struggle was the Second World War. Before this, institutionalists tended to dominate in a pragmatically inclined United States ${ }^{15}$. Afterwards, neoclassical economics became ascendant ${ }^{16}$, bolstered by a body of Keynesian macroeconomic thinking that became cast in terms of a 'neoclassical synthesis'.

The absorption of Keynes's ideas into neoclassical economics was important because it meant that institutionalist ideas were no longer necessary to justify significant government intervention in mixed economies. ${ }^{17}$ But, more importantly for economics, Keynes’s ‘third way’ emphasis upon the link between aggregative historical data and theories concerning the functioning of economic systems, such as the principle of effective demand, gradually became ignored. Keynes' theory was truly 'general' because it could encompass the historical experience of systems, as reflected in aggregate data, and economic theory that was history friendly. Furthermore, neoclassical economics was

\footnotetext{
${ }^{15}$ US institutionalism derived its power from the ascendant 'pragmatic' school of thought in American philosophy and science promoted by Charles Sanders Peirce, William James and John Dewey at the end of the $19^{\text {th }}$ Century.

${ }^{16}$ Neoclassical economics had English, French and Austrian origins in post-Enlightenment 'rationalist' philosophy.

${ }^{17}$ John Kenneth Galbraith fought tirelessly in the 1960s in his quest to persuade American policymakers that the true roots of Keynesianism were institutionalist but, despite his popularity and high profile, this was, in the end, to no avail.
} 
not abandoned but, instead, it was incorporated, in the Marshallian manner, in local and short period settings.

Keynes dug down below aggregate data in search of those aspects of processes that induce macro-instability. In the presence of uncertainty, constrained optimization was seen as secondary to behavior driven by emotional considerations ['animal spirits']. Also, in uncertainty, expectations were presumed to be interactive, i.e., opinion was deemed to be important and this provided the basis of his theory of liquidity preference, as a natural counterpoint to emotionally-driven business investment. None of this makes much sense in terms of neoclassical economic principles but is entirely consistent with a complex adaptive system perspective. Furthermore, the neoclassical conception of equilibrium, which was viewed as having no relevance at all to movements in macroeconomic data, was swept away in favor of a flow of funds concept of equilibrium that was set in the context of historical income-expenditure data. All this was all very novel and revolutionary and, of course, difficult to absorb by his peers. Keynes could not offer a coherent analytical treatment of what was a mixture of emotional responses to uncertain situations that lay deep in the genetic makeup of human beings and what Foster [2005] has termed as 'fourth order’ complex system behavior. Although the fragmentary nature of Keynes's macroeconomics meant that most economists could find something in the General Theory to relate to, it also meant that it was vulnerable to widespread attack, not for its policy recommendations for which there was wide consensus immediately after WWII, but for its perceived theoretical shortcomings. 
For, the ascendant institutionalists in the United States in the 1930s, Keynes' theory was viewed as too 'psychologistic', made too many concessions to neoclassical thinking [of the Marshallian type] and was deemed unnecessary to make the case for fiscally based stabilization policy. For neoclassical economists, the demotion of constrained optimization over production and utility functions to a supporting role, e.g., in the crucial area of business investment behavior, seemed, for many, to place Keynes' theorizing outside the domain of economics. Thus, Paul Samuelson felt he could say that "[I]t is remarkable that so active a brain would have failed to make any contribution to economic theory...” [quoted in Moggeridge [1976], p.156]. This is an important statement because it firmly delineates what was deemed acceptable and unacceptable theory amongst many prominent economists. This is underlined by the fact that Paul Samuelson, despite this critique of Keynes as a theorist, was a committed Keynesian in the policy arena.

In the decade that followed, Milton Friedman and other Chicago economists would offer more strident assertions that Keynes had strayed from the domain of economics in a fundamental way. Thus, it was no surprise that what Keynes offered as general became seen as specific [e.g., disequilibrium adjustment] and what was specific became seen as general [neoclassical equilibrium states]. Apart from straying from the neoclassical definition of economic theory, Keynes, quite deliberately, did not use the production function as a core analytical device in the General Theory - it only regained core status with the advent of the neoclassical synthesis. Famously, Keynes reversed Say's Law by abandoning the aggregate production function because it was regarded as meaningless in an economy that we can now label as a complex adaptive system. Monetary flows were 
seen as much more relevant to an understanding of why capitalist economies are prone to recessions and the associated underutilization of labor and capital. As has been pointed out, complex, interconnected economic systems, dependent on rules, rely, crucially, on the connective role of flows of funds.

From a complex adaptive system perspective, Keynes was correct to adopt this stance in dealing with aggregates since there can be no formal connection with diverse and shifting microeconomic production functions. ${ }^{18}$ Furthermore, the 'aggregated value' representation of the economy that Keynes dealt with is the summation of both spot and contractual transaction flows in a complex network structure of elements - the dichotomisation of aggregate demand and supply has no meaning in such a context. However, Keynes had no ambition to analyse the workings of a complex economic system in any detail. His main purpose was to carve up the national accounts in a simple way to establish that negative expenditure shocks could be countered by deficit financed government expenditure shocks in the opposite direction. Crucially, negative expenditure shocks were not viewed as random but, instead, driven by 'animal spirits' that involved persistent and amplifying shifts in the networks of opinion and belief that exist in states of uncertainty [Flieth and Foster [2002]]. It was precisely because of the non-random character of shocks that stabilization policy could be justified, a point never understood by New Classical economists and long forgotten by their New Keynesian bedfellows.

\footnotetext{
${ }^{18}$ The identification of a large residual in growth accounting and the observed instability in econometric models of aggregate business investment in the postwar era has provided strong vindication for Keynes' view that production function constructs are of very limited usefulness in macroeconomics.
} 
So Keynes had in his mind what we would now think of as a complex adaptive economic system. Quite erroneously, macroeconomists using neoclassical economic principles, have argued that Keynes offered a 'demand side' approach and neglected the 'supply side'. Although this has meaning in the neoclassical synthetic version of the Keynesian analytical framework it does not in the case of Keynes’ actual writings - there is no supply/demand dichotomy at the aggregate level in the complex economic system that he envisaged, only a network of connections through which income and expenditure flow in exchange for goods and services. Yes, at any point in time, a production function can be specified and it can be used to calculate how many factors of production are employed to produce the output that is added to the existing stocks that rise and fall over time due to demand fluctuations. But the animal spirits that give rise to productive efforts in the first place alter both supply and demand conditions over time as innovations in technology and organization occur. Thus, using an aggregate production function really tells us little or nothing about growth even though it can help us to track short-term movements of employment. For example, a bout of ‘expenditure pessimism' amongst investors or consumers will result in falls in income and rises in stocks of finished products and, consequently, cuts in production and employment in line with some contemporaneous production function relationship. So the availability of the most recent information on production relations can help us to predict what the income and employment effects of a negative shock will be in the next time period. For Keynes, this was about capacity utilization, not movements along a production frontier. 
Perhaps the most seriously misunderstood part of The General Theory is the discussion of the 'marginal efficiency of investment'. Neoclassical economists, such as Dale Jorgenson, ${ }^{19}$ viewed it as a misspecification of the neoclassical theory of capital and, accordingly, he tried to recast it in such terms. This was far off the mark because Keynes had attempted to do something radically different. He did not deny that variations in the price of capital goods and the cost of capital could affect the amount that a firm wishes to employ, i.e., constrained optimization does exist. Instead, he placed this association in a wider process of decision-making where a large part of the capital stock [a complex network structure] is irreversibly fixed. Thus, the only part of the capital stock that can be affected by the cost of capital is new investment. The real issue here, as Scott [1989] stressed, is whether it is gross or net investment that is associated with the cost of capital.

If we regard a firm as not just a complex system but also a dissipative structure then the relationship that Keynes proposed is correct - the capital stock that currently exists is not 'optimal', it is inherited from history and it is only new investment that can be subject to optimization exercises - 'bygones are bygones' as Alfred Marshall was fond of saying. But time irreversibility implies that constrained optimization is fraught with difficulty. The fact that there are significant sunk costs in the case of investments with long lives over periods of uncertainty makes decision-making both dangerous and adventurous. In a world of technological change and the rise and fall of products and processes, sensible investors certainly do use standard cost of capital calculations to explore different

\footnotetext{
${ }^{19}$ See Jorgenson [1963]
} 
scenarios and, undoubtedly, this eliminates very foolish decisions. However, the bulk of the decision has to be based on animal spirits driven by a combination of optimism concerning future returns from investment projects and fear that this will constrain future flexibility. Thus, optimization in relation to the cost of capital becomes a secondary aspect of investment decision-making. ${ }^{20}$

When we think of the economy as a complex adaptive system, we can see why Keynes was correct to downplay production function analysis and related production theory as the way to understand business investment at any level. In a sense, this was the greatest theoretical contribution in The General Theory. Regrettably, in the absence of a formal way of representing the main driving force of business investment, thinking in terms of production functions, involving the relative returns to labor and capital in the long run of a neoclassical optimization exercise, is where well-trained economists, such as Paul Samuelson, finished up. Decades would pass before Herbert Simon and Nicholas Georgescu-Roegen began to offer economists conceptualizations of human behavior in complex economic systems that could encompass Keynes’ insights and even more time would elapse before economists would (will?) become aware of the advances in complexity science that had been underway in the post WWII era, marked by Nobel Prizes for Ilya Prigogine [Chemistry] and, later on, Murray Gell-Mann [Physics].

\footnotetext{
${ }^{20}$ The econometric evidence supports this contention strongly. Investment is most strongly related to historical variables, i.e., combinations of lagged dependant and lagged income variables and only weakly related to cost of capital measures. Furthermore, such estimated equations are not found to be stable, i.e., they do not have equilibrium features.
} 
However, very few economists were equipped to follow this path and those who did were quickly classified as 'heterodox’ economists.

One of the limitations of Keynes's analysis is that the macroeconomic level of inquiry is inappropriate to capture the complexity of processes in an economic system - what we observe are the stock and flow of funds consequences of complex interactions. The elements and connections that make up the network structure of the economy and how this changes are, to a large degree, rendered invisible by aggregations of value flows and asset valuations. At the same time, a wholly microeconomic perspective that tries to build up from individual elements and connections is not very helpful either because so much behavior at that level constitutes component connections between elements embedded in higher level network structures. This is why Dopfer, Foster and Potts [2004] argue that 'meso-level' analysis, that identifies the generic rules that govern the behavior of complex systems, is most appropriate approach. There are many examples of complex network structures in the economy that are governed by generic rules that are meso in character. For example, as noted above, firms are increasingly looked on as complex adaptive systems in the management literature and many of the 'routines', identified by Nelson and Winter [1982] as the basis of understanding the behavior of the firm, also constitute meso rules.

When we examine a productive system, such as a firm, what we see are network structures in which elements are connected by flows that are energetic, material and virtual in nature. The movement of physical goods, both in the firm and outside it, can be 
associated with virtual instruments such as entries in accounts, promises to pay and the payment of some medium of exchange. Thus, connective flows that result in both the creation and the transfer of elements such as physical goods can have measurable values in a virtual dimension, i.e., a data field. Although a firm produces elements of value, in the form of goods for sale, this value arises from a complex network of connections, not from an aggregation of elements. This is why a production function is such a poor representation of the firm's productive process. As Williamson [1985] points out so powerfully, the firm is a governance structure, i.e., a network of connections. ${ }^{21}$

Traditional theories of value tend to be special cases of a connective theory of value. For example, the old labor theory of value is really about the value of the connections that workers forge in making products - it is a 'work' [or energetic] theory of value. The utility theory of value focuses upon the connections that are established between products and the preferences we have for them when purchase decisions are made - it is a subjective theory of value. Utility does not flow from an element such as a consumer durable but from the connections made between the durable and the consumer in use. Importantly, and again Oliver Williamson has contributed greatly to this, what is a connective network structure at one level can be an element at another - thus, we get a connective hierarchy.

\footnotetext{
${ }^{21}$ See Foster [2000b] for a discussion of the connections between transactions cost economics and complex adaptive systems theory.
} 
However, economists have not been entirely unaware of the importance of connections what they have tended to do is to make very strong and unrealistic assumptions about them, allowing the application of the mathematical tools of field theory. For example, 'markets' offer key connections in the economy and, by positing full information [full connectedness] in fully interconnected markets, each with supply and demand curves, a general equilibrium representation can be achieved. In the case of the firm, full information [full connectedness] allows economists to treat the firm as a single decisionmaking entity that can optimize in a way that permits a supply curve to be derived from its cost structure. We can think of this kind of economics as about over-connected, simplistic systems that, by definition, are not representations of reality. Although such system representations can be enlightening in coming to an understanding how prices might move in approximately static circumstances, they cannot capture the behavior of the economy and its components over time in a satisfactory way.

Economies and their constituent firms are network structures in which connections are limited and thus, they are complex systems. Connections that are definably 'economic' are those that have a monetary value attached, i.e., flows of funds exist. Thus, income and expenditure flows are much more important than price variations in the production as distribution of goods and services. In firms, the goal is to discover organizational connections that deliver value added and, externally, the firm’s marketing person/team seeks to discover connections with purchasers that result in flows of revenue. These connections generate value evolve over time for different firms [asset value] and different products [flow value]. As this evolution proceeds, we tend to observe growth that traces 
out something like a logistic path as new connections are forged, existing ones become more reliable and others fall into disuse. This connective structure constitutes a set of rules, some which remain idiosyncratic and some that will become generic, ie, they have a meso character. ${ }^{22}$

In analyzing such processes in terms of network theory, rather than production function analysis, a novel product that is introduced outside existing production networks will be produced locally and individual producers will tend to form a random network with adjacent connections to each other. Typically, these are not competitive connections but, rather, cooperative ones, as producers are eager to learn from each other in improving both product and production processes. From a straightforward game theoretic perspective, the anticipated returns from cooperation exceed those involved in a competitive standoff. Inevitably, this produces a great deal of variety in both products and processes and replicator dynamics will operate across this variety, again, not so much due to direct competition but because the most attractive products can reach a wider market, as producers of less attractive variants are persuaded to become components of larger production networks through agency agreements, franchises, etc. Although the physical movement of products to customers still has to go through conventional distribution channels, it is virtual connections, through the mail system, the telephone system, the visits of representatives and, now, the internet that are crucial. Ultimately

\footnotetext{
22 Hayek [1967] viewed the emergence of generic rules as a process of 'spontaneous order' and, more recently, Foster and Wild [1999] have called this 'economic self-organization'.
} 
such processes are likely to result in the formation of a few hubs in a scale free network that has a value distribution that can be represented by a power law. ${ }^{23}$

It is this kind of complex network characterization of production that provides a mesofoundational basis for Keynes's macroeconomics. Undoubtedly, in these networks, we can observe many of the strategic interactions that have been analyzed using game theory and, in this sense, game theoretic microeconomics is entirely complementary to complex adaptive systems theory [Sent [2004]]. However, what is urgently needed is the development of new theories concerning the emergence, maintenance and decline of meso rules since it is these that stand between the macro and the micro and provide the order and continuity in the economic system that allow us to consider it a 'system' rather than some kind of statistical 'random walk'.

\section{Concluding Remarks}

The economy is a complex adaptive system. This was grasped intuitively by, among others, Alfred Marshall, John Maynard Keynes and, of course, Joseph Schumpeter. However, over the past half century, developments in economics have not been based upon these intuitions to any significant extent. Instead, constrained optimization became the cornerstone of a 'modern' economics in which theories were constructed upon this particular kind of behavioral rule. In the Cold War era, significant ideological advantages came from the emphasis in neoclassical economics upon individual freedom of choice

\footnotetext{
${ }^{23}$ See Barabasi [2002] for further discussion of these network dynamics.
} 
and the presumption that well-functioning markets offered the best means of allocating resources. With respect to scientific progress, however, the cost of has been high because the range of theoretical models in which it is possible to operationalize such optimization is quite restrictive and, in consequence, a range of assumptions have to be made before such models can be used deductively. Importantly, historical time is usually removed, rendering theories simplistic, i.e., they are out of contact with historical processes. Game theory, despite its applicability in many contexts, is also outside historical time because it is a situation specific logic that focuses upon outcomes based upon strategic considerations, i.e., it cannot offer any general representation of multi-agent processes as they unfold in time.

The production function is a central construct in modern economics. It has been argued that it is an inadequate construct for the purpose of understanding how economic processes operate. To some extent, this has been recognized in endogenous growth theory but such theorizing does not go nearly far enough [Metcalfe, Foster and Ramlogan [2004]]. Complex adaptive systems have to be understood as network structures and their evolution involves change and expansion in such networks. Remarkably, Keynes developed an approach to economics that is very sympathetic to the view that the economy is a complex adaptive system. The influence of Alfred Marshall was clearly a main source of his radical perspective. However, in Keynes' day, the notion of complex systems had hardly begun to develop, even in the natural sciences, so all that he could offer was a set of connected intuitions that were so alien that some economists did not even recognize them as belonging to economic theory. Even Joseph Schumpeter, who 
also offered insights that can be seen as residing within a complex systems perspective, found it difficult to acknowledge Keynes’s remarkably innovative achievements, preferring to heap praise upon Leon Walras, who laid down the analytical foundations upon which the premier simplistic approach to economic theory would be constructed in the post-Second World War era .

In many ways, to further the complex systems perspective in economics, we have to wind the clock back - to Alfred Marshall’s struggle with time, to Keynes’s General Theory and to the powerful critique of neoclassical economics launched by Friedrich Von Hayek before he left the community of economists in disgust to join the lawyers in Chicago. In the 1960s, Nicholas Georgesecu Roegen and Herbert Simon offered compelling research agendas for the construction of a replacement for neoclassical economics but these were largely ignored or cherry picked to bolster established theories, e.g., the adoption of Simon’s rational expectation idea in new classical macroeconomics. However, being timeless, neoclassical economics has been difficult to supplant because, unconstrained by the evidence of history, it has been an infinitely malleable vehicle for clever ideas, especially when economic analysis became much more interactive through the use of game theory.

Once upon a time, neoclassical economics was thought to offer a unified analytical framework but both the advance of game theoretics and changed ideological priorities, since the end of the Cold War, have yielded a very specialized and fragmentary economics. Policymakers who used to be comfortable in the tractable world of simplistic 
neoclassical economics are now very bemused by the technical sophistication and complicatedness of the models that they are expected to employ in policy formulation. This is, of course, a prescription for non-intervention but, in a world where government intervention remains very significant, it also implies that political priorities are free to dominate in formulating government taxation and spending choices. What economic progress constitutes is no longer clear because we do not have any clear systemic view of how the economy and its components work and change.

Both Alfred Marshall and Maynard Keynes began to think of the economy in complex system terms and, in so doing, they produced analytical frameworks that were broadly intelligible to a wide audience. The eight editions of the Principles of Economics and the one edition of the General Theory were never equaled in the $20^{\text {th }}$ Century in terms of their influence upon policymakers and the public at large. Each teased out different aspects of the economy as a complex system and provided analytical frameworks that could be understood by policymakers. The challenge is, once again, to provide some relatively straightforward analytical principles that can shed light upon behavior of the complex economic system that we have today. This will not be an easy task because, as Maynard Keynes noted, there is never a shortage of cleverness, only wisdom, in the community of economists.

Economic wisdom involves a capacity to see which particular aspects of a complex system are crucial in any particular epoch and to provide a straightforward analytical framework in which they can be handled. This has to be done in a way that is not too 
general as to become valueless and not so theoretical that it loses connection with historical experience. Typically, advances of this type in economics do not occur in a vacuum - the General Theory was a child of the Great Depression. This is largely why the wisdom of, for example, Herbert Simon and Nicholas Georgescu-Roegen did not attract much attention in the 1960s, an era of prosperity and growth in which inflation began to be viewed as the main economic problem. The emergence of stagflation led to a new analysis of inflation in terms of amplified expectational feedback loops which, although ultimately set in within very conventional economic models, echoed the work of Herbert Simon and others dealing with the analysis of systemic feedbacks back in the 1950s. Although not usually thought of in this way, the 'expectational revolution' in macroeconomics represented an advance towards a complex adaptive system perspective on the economy. It remains to be seen what great economic problem will arise next to provide a fertile environment for the further advance of complex systems science in economics.

\section{References}

Alchian, A.A., “Uncertainty, evolution and economic theory.” Journal of Political Economy, 58 (1950), 211-22.

Anderlini, L. and L. Fell, “Costly bargaining and renegotiation.” Econometrica, 69 (2001), 377-411.

Axelrod, R. and M.D. Cohen, Harnessing Complexity: Organizational Implications of a Scientific Frontier (New York, NY: Free Press, 1999).

Barabasi, A.L, Linked: the New Science of Networks (New York, NY: Perseus, 2002).

Bowles, S. and H. Gintis, "Walrasian economics in retrospect.” Quarterly Journal of Economics, 115, 1411-39.

Brooks, D.R. and E.O. Wiley, Evolution as Entropy: Toward a Unified Theory of Biology (Chicago, IL: Chicago University Press, 1986).

Byrne, D., Complexity Theory and the Social Sciences: An Introduction, (London: Routledge, 1998).

Depew D. J and B.H. Weber, Darwinism Evolving: System Dynamics and the Geneology of Natural Selection (Cambridge, MA.: MIT Press, 1995). 
Dopfer, K., J. Foster and J. Potts, “Micro-meso-macro.” Journal of Evolutionary Economics, 14 (2004), 263280.

Flieth, B and J. Foster, “Interactive expectations.” Journal of Evolutionary Economics, 12 (2002), 375-396.

Foley, D., Unholy Trinity: Labour, Land and Capital (London: Routledge, 2003).

Foster , J., "Is there a role for transactions cost economics if we view firms as complex adaptive systems?" Contemporary Economic Policy, 18 (2000b), 369-385.

Foster, J. and J. Metcalfe, Frontiers of Evolutionary Economics: Competition, Self-Organization and Innovation Policy (Cheltenham: Edward Elgar, 2001).

Foster, J. and P. Wild, “Econometric Modelling in the Presence of Evolutionary Change.” Cambridge Journal of Economics. 23 (1999), 749-770.

Foster, J., “Competitive Selection, Self-Organization and Joseph A. Schumpeter.” Journal of Evolutionary Economics, 10 (2000a), 311-328.

Foster, J., "Economics and the self-organisation approach: Alfred Marshall revisited?” The Economic Journal, 103 (1993), 975-91

Foster, J., "From simplistic to complex systems in economics.” Cambridge Journal of Economics, 29 (2005), forthcoming. [Earlier version presented at the Economics for the Future Conference Cambridge [UK],17-19 ${ }^{\text {th }}$ September 2003].

Freeman, C. and C. Louça, As Time Goes By: From the Industrial Revolutions to the Information Revolution (Oxford: Oxford University Press, 2001).

Friedman, M., "The methodology of positive economics," in Essays in Positive Economics. M. Friedman, ed. (Chicago, IL: University of Chicago Press, 1953).

Hayek, F., “The theory of complex phenomena,” in Studies in Philosophy, Politics and Economics, F. Hayek, ed. (Chicago, IL: University of Chicago Press, 1967).

Hayek, F., The Counter-Revolution of Science: Studies in the Abuse of Reason (Glencoe, IL.:The Free Press, 1952).

Holland, J., Hidden Order: How Adaptation Builds Complexity (Reading, Mass.: Helix Books, 1995).

Jorgenson, D., "Capital theory and investment behavior." American Economic Review. 53 (1963), 247-259.

Kauffman, S.A., The Origins of Order; Self-Organization and Selection in Evolution (New York, NY: Oxford University Press, 1993).

Keynes, J.M., The General Theory of Employment, Interest and Money ( London: Macmillan, 1936).

McElroy, M.W., The New Knowledge Management : Complexity, Learning, and Sustainable Innovation (New York, NY: Butterworth-Heinemann, 2002).

McKelvey, B., "Complexity theory in organization science: seizing the promise or becoming a fad? Emergence, 1 (1999), 3-32.

Metcalfe, J.S., Evolutionary Economics and Creative Destruction (London: Routledge, 1998).

Metcalfe, J.S., J. Foster. and R. Ramlogan, “Adaptive economic growth.” Cambridge Journal of Economics, 29 (2004), forthcoming.

Mirowski, P., More Heat Than Light: Economics as Social Physics. (New York, NY: Cambridge University Press, 1989).

Moggeridge, D.E., Keynes. (London: Macmillan, 1976).

Nelson, R. and S. Winter., An Evolutionary Theory of Economic Change (Cambridge, MA.: Belknap Press of Harvard University Press, 1982).

Penrose, E.T., "Biological analogies in the theory of the firm." American Economic Review, 42 (1952), 809-19.

Popper, K., The Open Society and its Enemies [2 vols.]. (London: Routledge, 1945).

Popper, K., The Poverty of Historicism (London: Routledge, 1944).

Potts, J., The New Evolutionary Microeconomics: Complexity, Competence and Adaptive Behavior (Cheltenham: Edward Elgar, 2000).

Rosser Jnr, J.B., “On the complexities of complex economic dynamics.” Journal of Economic Perspectives. 13 (1999), 169-192.

Scott, M. F.G., A New View of Economic Growth (Oxford: Oxford University Press, 1989).

Sent, E.M., "'The legacy of Herbert Simon in game theory.” Journal of Economic Behavior and Organization, 53 (2004), 303-317.

Stacey, R.D., Complexity and Creativity in Organizations (London: Berrett-Koehler, 1996). 
Vanberg, V., “The rationality postulate: its ambiguity, its deficiency and its evolutionary alternative.” Journal of Economic Methodology. 11 (2004), 1-29.

Veblen, T.B., "Why is economics not an evolutionary science?” Quarterly Journal of Economics, 12 (1898), 373-426.

Velupillai, K., Computable Economics, the Arne Ryde Memorial Lectures, Oxford: Oxford University Press, 2000).

Weintraub, E.R., How Economics Became a Mathematical Science, (Durham, NC: Duke University Press, 2002).

Williamson, O.E., The Institutions of Capitalism, (New York, NY: Free Press, 1985). 